\title{
WETLANDS CONSTRUÍDOS: ESTUDO DE CASO Parc du Chemin de I'lle E APLICABILIDADE EM MUNICÍPIOS BRASILEIROS SOB A PERSPECTIVA DA ECOLOGIA E ECONOMIA
}

\footnotetext{
Marina Soares Godinho - marinagsoares1@hotmail.com

Fundação Mineira de Educação e Cultura (Universidade FUMEC)

Juliana da Silva e Mascarenhas Guedes - jsguedes@fumec.br

Universidade Fernando Pessoa - PORTO - PORTUGAL

Fundação Mineira de Educação e Cultura (Universidade FUMEC)
} 


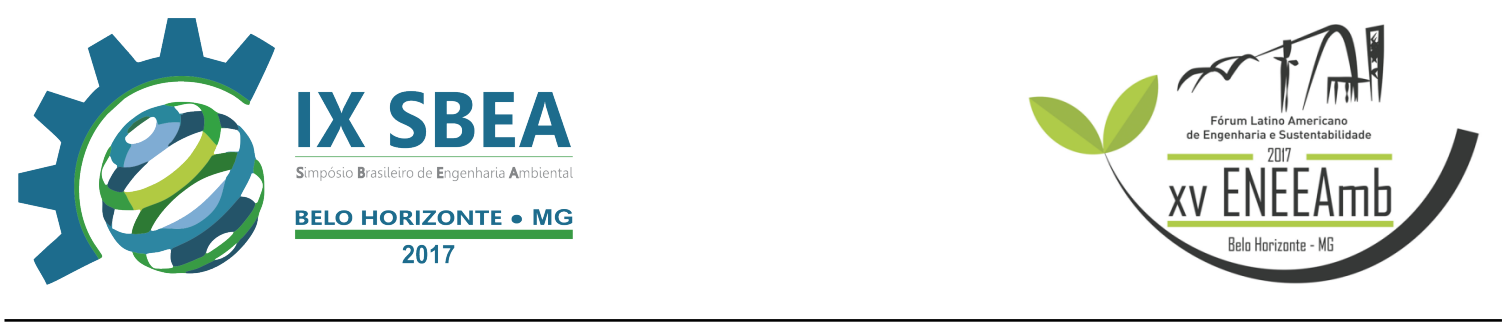

\section{RESUMO}

Os Wetlands Construídos (WC) são sistemas concebidos para utilizar processos naturais, que envolvem vegetação, materiais filtrantes e microrganismos. Eles são uma tecnologia pouco conhecida no Brasil, porém são uma possível solução para o saneamento do nosso país. A nossa demografia é favorável para pequenos sistemas, já que a maior parte dos municípios possui até 15000 habitantes. Além disso, foi constatado que somente $50 \%$ da população brasileira possui acesso à coleta de esgoto. E, como o Brasil ainda é considerado um país em desenvolvimento, o melhor seria utilizar tecnologias mais simplificadas, devido à dificuldade de operação no caso das mais avançadas. Assim sendo, os WC são o sistema ideal para o país nestes diversos quesitos, além de serem mundialmente reconhecidos por sua elevada eficiência operacional e sua harmonia paisagística. Já existem milhares destes ao redor do mundo, sendo a maior concentração na Europa. Na França existem cerca de 3500 sistemas wetlands construídos implantados, maior que o número de ETEs no Brasil inteiro. Um exemplo a ser explanado será o Parc du Chemin de I'lle, onde há processos de despoluição do Rio Senna, na cidade de Nanterre, França..

Palavras-chave: Wetlands construídos. Sustentabilidade. Saneamento. Macrófitas; Tratamento de efluentes.

\section{INTRODUÇÃO/OBJETIVO}

O presente trabalho consiste no estudo conceitual de um Wetland construído como alternativa para tratamento de efluentes.

Os Wetlands construídos (WC) são sistemas artificialmente construídos que mimetizam o funcionamento de áreas alagadas naturais, visando o tratamento de efluentes líquidos. De forma controlada, os WC utilizam o mesmo princípio de modificação da qualidade da água que as áreas alagadas naturais, valendo-se da retirada de nutrientes e matéria orgânica do sistema pelo metabolismo das plantas aquáticas (SALATI; SALATI, 1999). Estes sistemas são geralmente usados para o tratamento secundário ou terciário de efluentes (BRIX, 1994), necessitando de tratamentos preliminares e/ou primários, de acordo com a qualidade do efluente a ser tratado. 


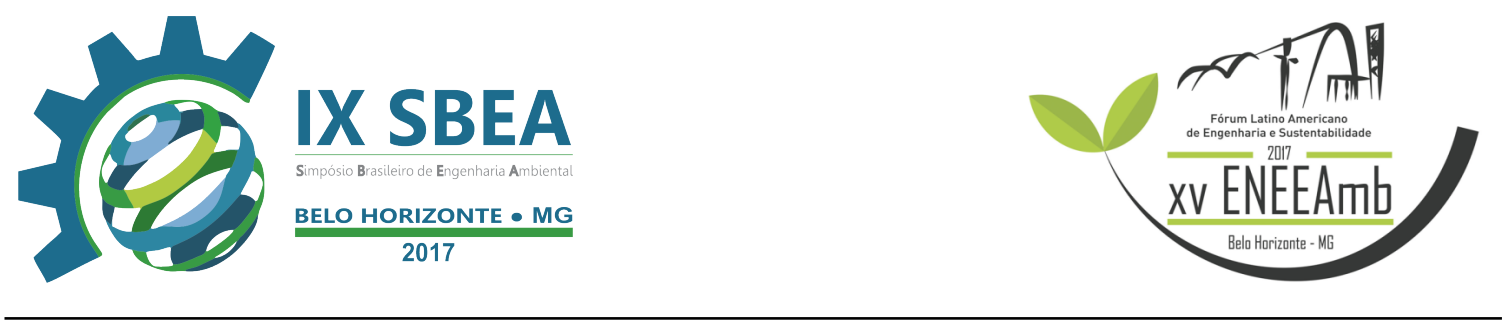

Os WC vêm ganhando importância como uma alternativa efetiva e de baixo custo para tratamento de efluentes líquidos, além de possuírem vantagens sobre o sistema convencional de tratamento (SIRACUSA; LA ROSA, 2006) como, por exemplo, instalação próxima às fontes produtoras de esgoto, baixa necessidade de consumo de energia e de treinamento da mão de obra para manutenção do sistema.

\section{METODOLOGIA}

O trabalho desenvolvido tem natureza básica, produzindo conhecimento a ser utilizado em outras pesquisas. Tem como objetivo uma pesquisa descritiva, pois define as características da população de pessoas em situação de rua da cidade de Contagem. Possui uma abordagem quantitativa requerendo o uso de recursos e técnicas, traduzindo tudo em números a partir de estudos estatísticos. Quanto aos procedimentos utiliza-se da rogativa de informações, por meio de análise quantitativa obtivemos conclusões.

\section{RESULTADOS E DISCUSSÃO}

\subsection{Resultados positivos de aplicação do sistema}

Os wetlands construídos já foram implantados em diversas partes do mundo, já são mais de 32 países que utilizam com sucesso essa tecnologia. Na França, por exemplo, há mais de 3500 sistemas em funcionamento (MEYER et al., 2015). No Brasil também estão sendo implantados em algumas regiões, e os resultados mostrados são, em quase todos os casos, favoráveis. Isso porque os WC, além de apresentarem inúmeras vantagens comparados a outros sistemas de tratamento de esgoto, ficam mais convenientes ainda devido às condições atuais do nosso país, porque são baratos e de simples operação e manutenção, além da ausência de lodo a ser tratado.

Uma pesquisa realizada pela empresa Rotatória do Brasil (SEZERINO et al., 2003) em que reúnem-se 100 trabalhos publicados no Brasil de wetlands construídos (principalmente para o tratamento de esgoto doméstico), entre 1999 e 2011, mostra os seguintes resultados: 


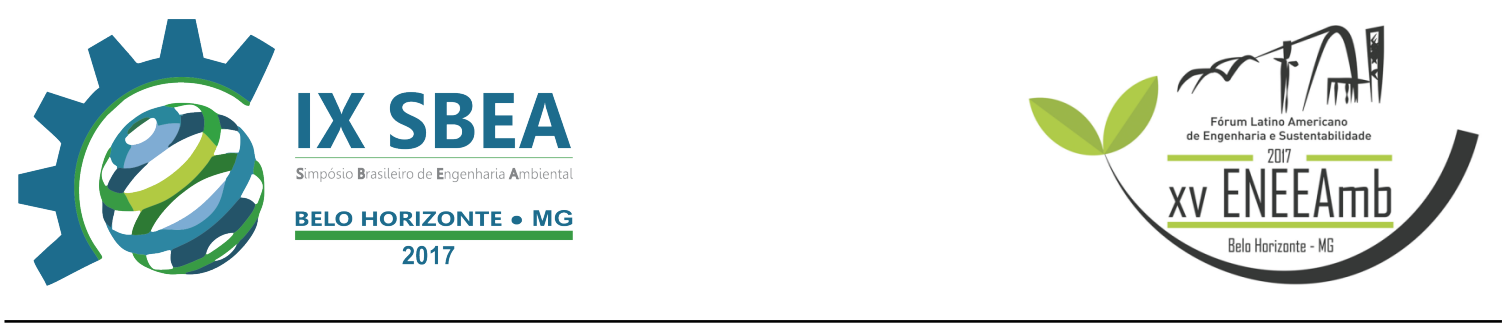

$\checkmark$ remoção de $90 \%$ de $\mathrm{DBO}_{5}$;

$\checkmark$ remoção de $90 \%$ de SS;

$\checkmark$ remoção de $20 \%$ de Amônia;

$\checkmark$ remoção de $30 \%$ de Fósforo.

Como qualquer outra tecnologia, os wetlands construídos apresentam diversas vantagens e desvantagens que são resumidas no quadro 01 .

Quadro 01 - Principais vantagens e desvantagens dos wetlands construídos

\begin{tabular}{|c|c|c|}
\hline WETLANDS CONSTRUÍDOS & VANTAGENS & DESVANTAGENS \\
\hline Custos implantação & Baixos & - \\
\hline Custos manutenção & Baixos & - \\
\hline Consumo de energia elétrica & Baixo & - \\
\hline Manutenção & $\begin{array}{l}\text { Não requer mão de obra } \\
\text { qualificada, produtos químicos e } \\
\text { equipamentos complexos }\end{array}$ & - \\
\hline Eficiência do tratamento & $\begin{array}{c}\text { Remoção satisfatória de matéria } \\
\text { orgânica, sólidos suspensos, } \\
\text { organismos patógenos, nitrogênio e } \\
\text { fósforo. }\end{array}$ & $\begin{array}{l}\text { Colmatação, havendo necessidade } \\
\text { do controle da carga hidráulica e de } \\
\text { sólidos. Alguns compostos } \\
\text { orgânicos removidos pelo sistema } \\
\text { podem ser vinculados aos } \\
\text { sedimentos e se acumularem ao } \\
\text { longo do tempo. }\end{array}$ \\
\hline Paisagismo & $\begin{array}{l}\text { Contribuem com a estética } \\
\text { podendo ser usadas macrófitas } \\
\text { ornamentais, permitindo a criação } \\
\text { de espaços verdes e áreas } \\
\text { recreacionais }\end{array}$ & - \\
\hline Reuso & $\begin{array}{l}\text { Permite reuso na agricultura e } \\
\text { piscicultura }\end{array}$ & - \\
\hline Biomassa & $\begin{array}{c}\text { Pode ser utilizada na produção de } \\
\text { energia, ração animal e } \\
\text { biofertilizantes }\end{array}$ & - \\
\hline Produção residual & Não há & - \\
\hline
\end{tabular}




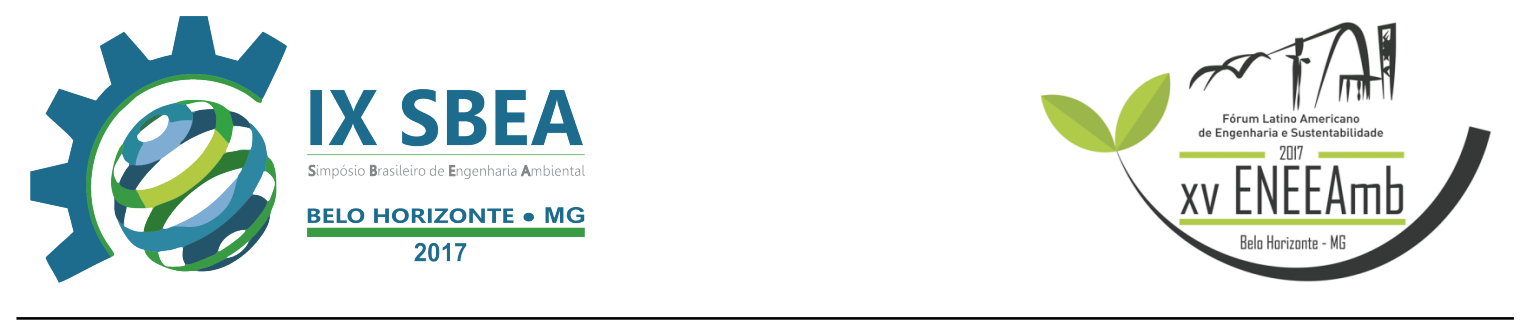

\begin{tabular}{|c|c|c|}
\hline Vetores & $\begin{array}{c}\text { Não são observadas em sistemas de } \\
\text { fluxo subsuperficial }\end{array}$ & $\begin{array}{c}\text { Insetos e mosquitos podem ser } \\
\text { observados em sistemas de fluxo } \\
\text { superficial }\end{array}$ \\
\hline Área & - & Requerem grandes áreas \\
\hline Clima & $\begin{array}{c}\text { Tolerância a flutuações no ciclo } \\
\text { hidrológico }\end{array}$ & $\begin{array}{c}\text { Necessidade de caracterização } \\
\text { específica do ciclo hidrológico e } \\
\text { regime de temperatura }\end{array}$ \\
\hline Comunidade biológica & - & $\begin{array}{c}\text { Sensitiva a substâncias químicas } \\
\text { tóxicas (amônia e pesticidas) }\end{array}$ \\
\hline Poluentes & - & $\begin{array}{c}\text { Picos de poluentes podem reduzir a } \\
\text { eficiência do tratamento }\end{array}$ \\
\hline
\end{tabular}

Fonte: Adaptado de Nascimento e Chaves (2015); Boschilia, Junior e Boschilia (2014).

\subsection{Funcionamento de Wetland Construído}

Wetland Construído é um sistema de tratamento de efluentes projetado de forma artificial, que utiliza-se de plantas aquáticas, as chamadas macrófitas, cultivadas sobre materiais como areia, solo ou cascalho, ocasionando a proliferação de biofilmes. Cada elemento atuante no sistema WC constitui função essencial na depuração da carga poluente a ser tratada. As plantas macrófitas, com seus rizomas, criam redes de convivência para as bactérias que se servem da matéria orgânica abundante e expandem sua comunidade. Desse processo, as bactérias anaeróbias produzem os compostos inorgânicos que retribuem às plantas, a energia capaz de manter viva a sinergia do ecossistema artificial. (DE SOUSA et al., 2000)

O quadro 02 apresenta os mecanismos predominantes de remoção de poluentes nos WC. (COOPER; FINDLATER, 2013)

Quadro 02 - Mecanismos predominantes na remoção de poluentes nos WC

\begin{tabular}{|c|c|}
\hline CONSTITUINTES DO ESGOTO & MECANISMOS DE REMOÇÃO \\
\hline Sólidos Suspensos & Sedimentação, filtração. \\
\hline Material Orgânico Solúvel & $\begin{array}{c}\text { Degradação microbiológica aeróbia, } \\
\text { degradação microbiológica anaeróbia. }\end{array}$ \\
\hline Nitrogênio & $\begin{array}{c}\text { Amonificação seguido de nitrificação e } \\
\text { desnitrificação microbiana, retirada pela } \\
\text { planta, adsorção, volatilização da amônia. }\end{array}$ \\
\hline
\end{tabular}




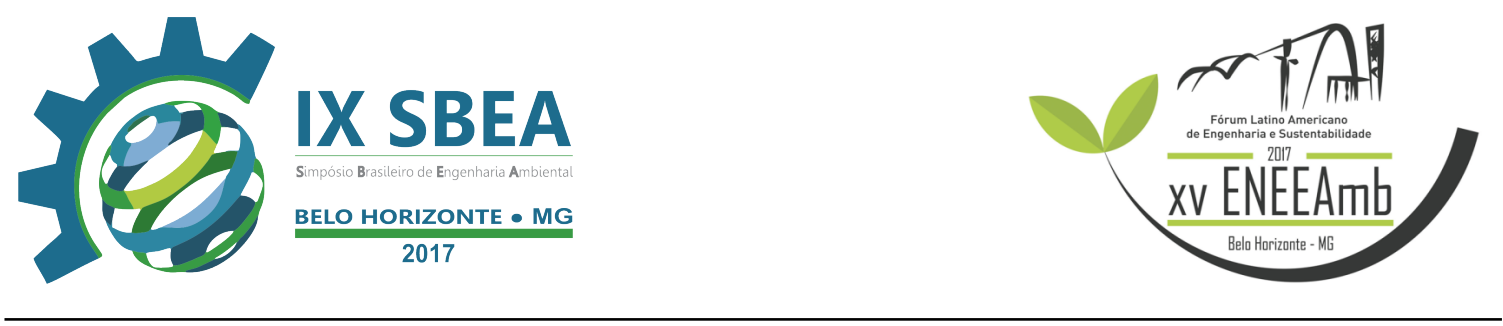

\begin{tabular}{|c|c|}
\hline Fósforo & Adsorção, retirada pela planta. \\
\hline Metais & $\begin{array}{c}\text { Complexação, precipitação, retirada pela } \\
\text { planta, oxidação/redução microbiana. }\end{array}$ \\
\hline Patogênicos & Sedimentação, filtração, predação. \\
\hline
\end{tabular}

Fonte: Adaptado de Cooper (2003).

As WC são classificadas em dois grandes grupos de acordo com o regime de escoamento do líquido e esses grupos podem ser subdivididos de acordo com o fluxo hidráulico em seu interior. Além disso temos uma separação de acordo com o tipo de macrófitas utilizadas.(KADLEC et al., 2000)

A figura 01 mostra a separação dos principais grupos e suas subdivisões.

Figura 01 - Tipos de wetlands construídos de acordo com o escoamento do

fluxo

(a) Wetlands fluxo superficial 


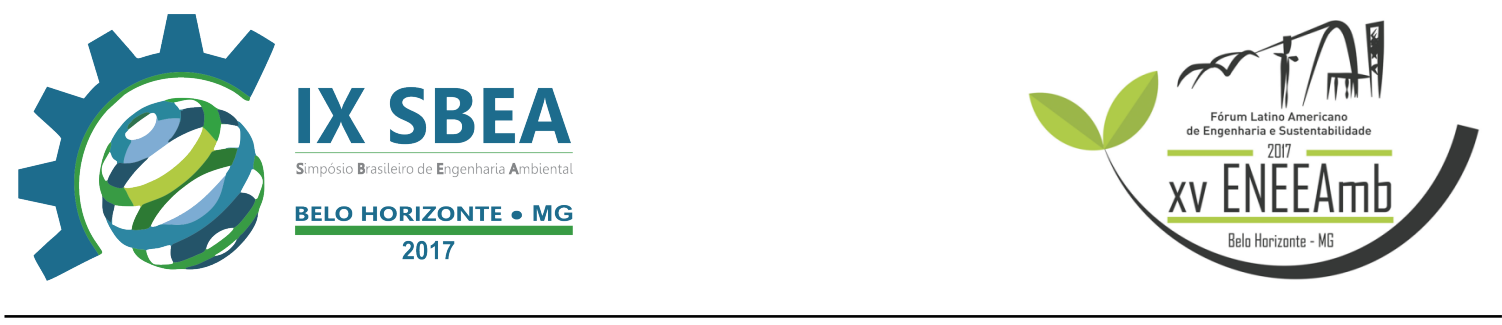

Nos sistemas de wetlands horizontais de fluxo subsuperficial, não há necessidade de mecanização ou uso insumo energético para operação do sistema. $\mathrm{O}$ fluxo de efluente flui por gravidade através do filtro de areia, de forma horizontal e abaixo do solo onde se encontram as plantas. Dessa forma a Wetland de fluxo horizontal se apresenta como melhor alternativa para o projeto em questão.

O tipo de filtro mais recomendado pela literatura em todo o mundo é a areia combinada com a brita. A areia exerce a função de filtro e a brita exerce a função de anteparo dissipador de energia na seção de entrada e a função de dreno na seção de saída do fluxo do efluente.

A figura 02 mostra a separação dos principais grupos e suas subdivisões

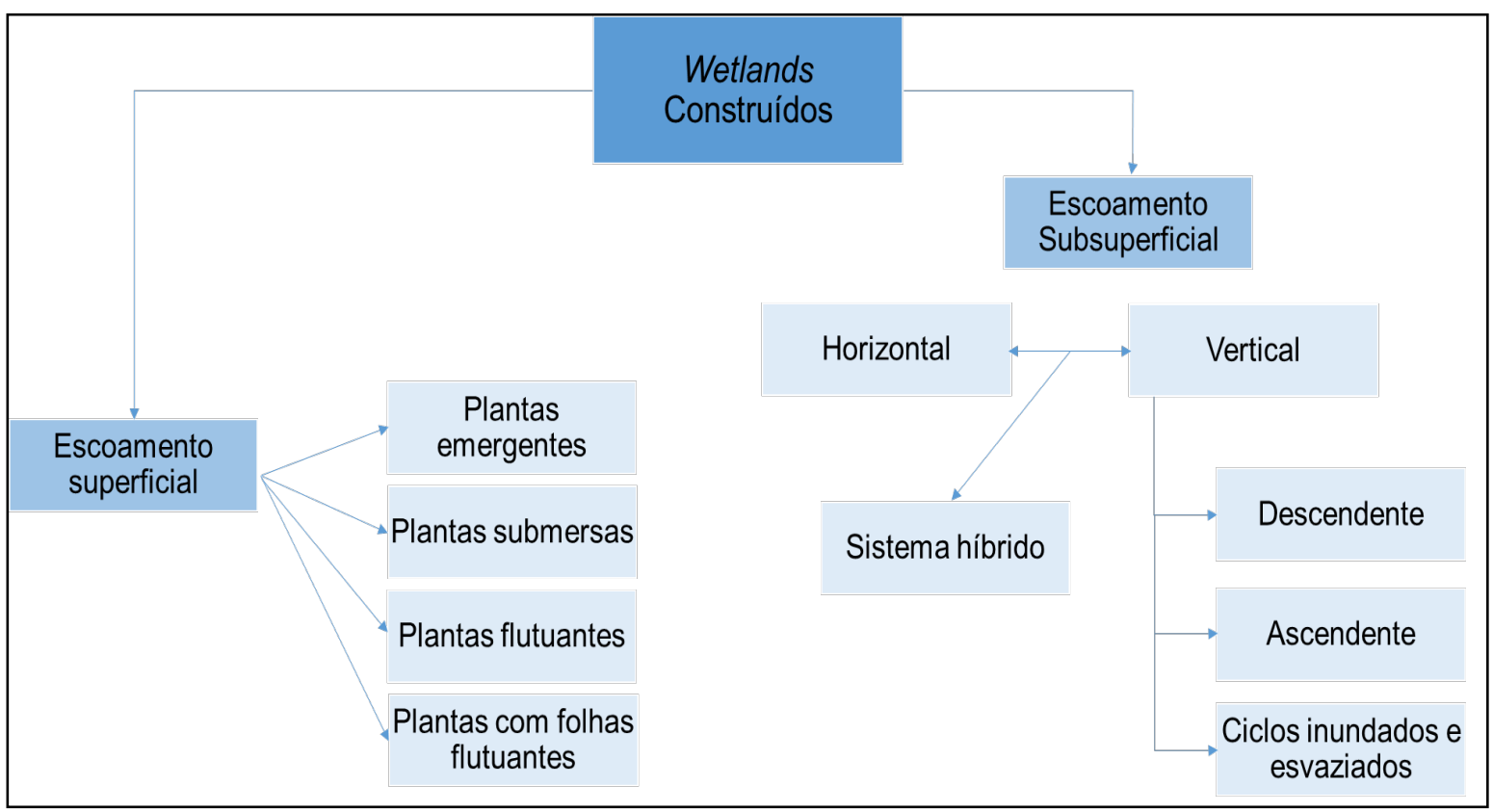

Fonte: Adaptado de Salati (1999) 


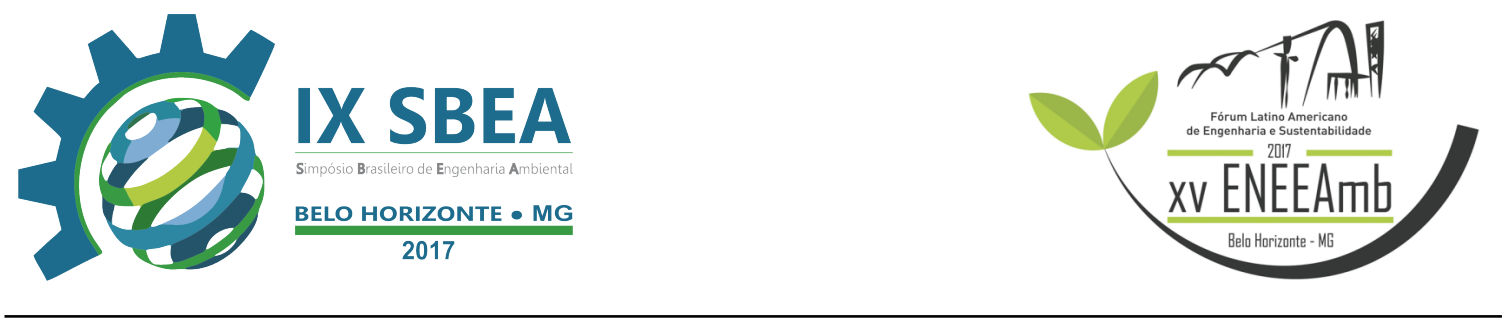

\subsection{Estudo de Caso: Parc du Chemin-de-I'lle, Nanterre, França}

O Rio Sena é o mais importante rio da França, porém ao longo dos anos, ele foi muito poluído e já estava considerado condenado. Contudo, os franceses investiram muito na sua recuperação, e estudos já mostram o sucesso dessa restauração.

Na cidade de Nanterre especificamente, há uma grande ação de revitalização urbana que é o Parc du Chemin de I'lle, onde tecnologias são utilizadas para contribuir com a despoluição do Rio Sena por meio de sistemas naturais integrados, dentre eles os wetlands construídos. (FIGURA 03)

Figura 03 - Parc du Chemin de I'lle

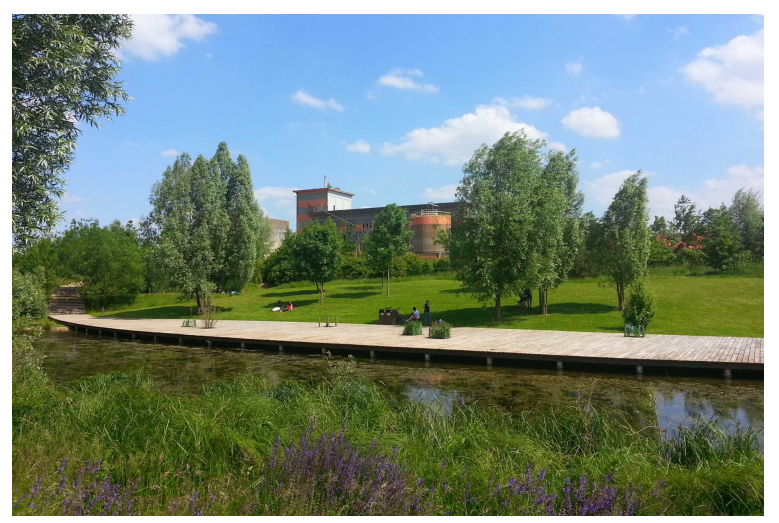

Fonte: Meyer (2015)

Seu funcionamento consiste em uma sequência de piscinões, na entrada do local, que filtram e despoluem a água bombeada do rio, transportada por meio de um parafuso de Arquimedes e purificada pelas plantas presentes nas piscinas. Na primeira destas, contém a Typha angustifólia e Phtagmites Communis que retiram as cargas poluentes e reduzem as taxas de nitratos, metais pesados e matérias orgânicas em suspensão. A segunda piscina utiliza Equisetum fluviatile, Iris pseudacorus e Iris sibirica para eliminar germes, suprimindo as bactérias. Os últimos piscinões contêm plantas oxigenantes, além de atestarem a boa qualidade da água pela presença de lírios, que só 


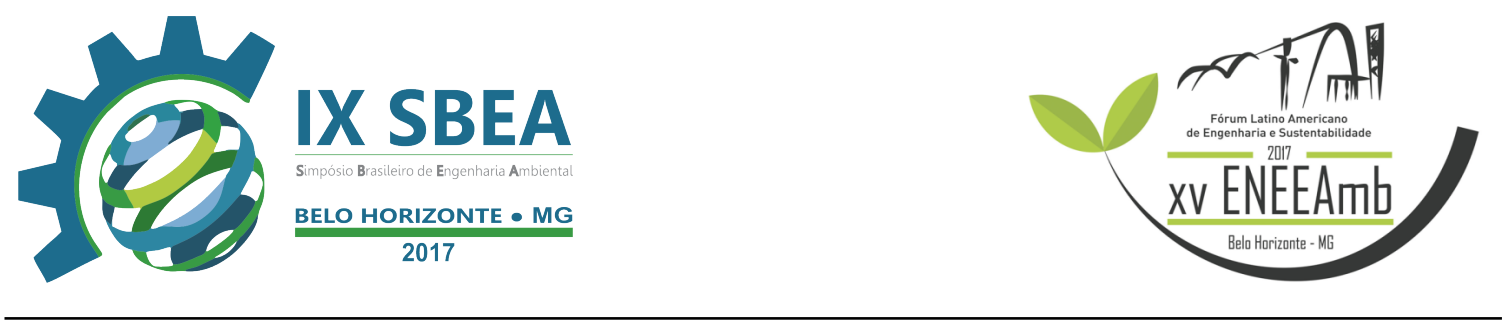

se desenvolvem em águas com taxas de oxigênio satisfatórias. E, finalmente, a água limpa que sai desses processos é utilizada para irrigação de hortas comunitárias no parque.

Os resultados desses wetlands foram extremamente satisfatórios pois a água que entra do Sena carrega compostos orgânicos, nitrogênio, fósforo e germes e tem uma qualidade de água classe 3 (sistema francês). Já, na saída, alcança a qualidade 1B, que seria "água para banho". Além disso, não só o parque produz entre 40 e $80 \mathrm{~m}^{3}$ de resíduos verdes que são reutilizados no local, bem como não é utilizado nenhum tipo de produto químico no processo.

\section{CONCLUSÕES/RECOMENDAÇÕES}

Conclui-se que, os wetlands construídos são uma alternativa para o tratamento de efluentes com menores investimentos principalmente por sua tecnologia ser de fácil instalação, operação e manutenção, além do seu custo operacional vantajoso.

A escolha do tipo de wetlands baseia-se na análise da eficiência, disponibilidade de área para instalação e principalmente no fato dessa alternativa ser capaz de receber esgotos brutos e não liberar odores desagradáveis. Esses critérios são considerados importantes devido ao fato das wetlands poderem ser o único tratamento adotado e ser instalada na proximidade das residências; na zona urbana.

Ressalta-se a viabilidade técnica do sistema que, embora ainda em processo de difusão no Brasil, já se encontra em operação há vários anos em outros países tendo sua eficiência comprovada pelos anos de utilização.

Os wetlands construídos ajudam o homem a reconfigurar o meio ambiente anulando os impactos que ele próprio vem causando, além de suas diversas outras vantagens.

Esse estudo poderá ser utilizado como um modelo de otimização do sistema com auxilio do sistema arduíno. O arduíno é uma plataforma eletrônica programável que pode ser utilizada para auxiliar nos controles de temperatura e umidade. No caso das 


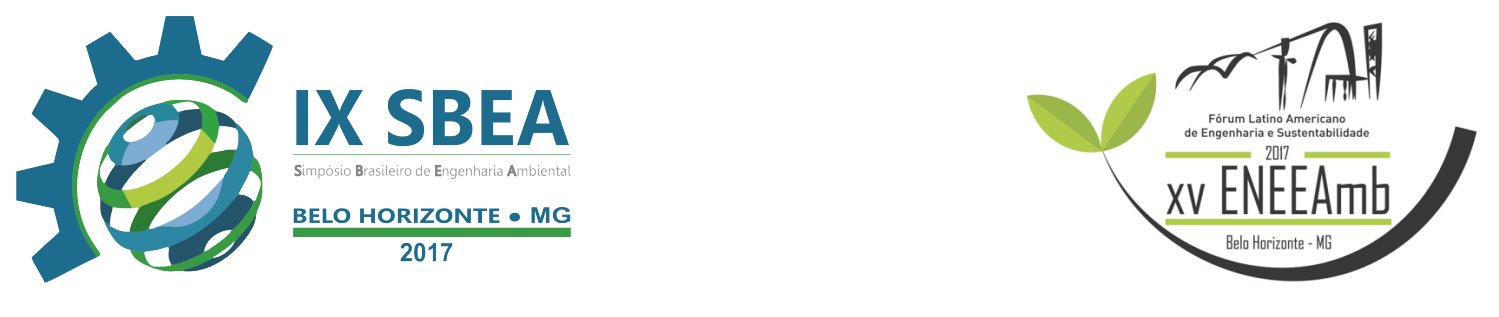

wetlands, os arduínos podem ser usados para viabilizar a escolha mais assertiva da espécie (macrófita) de acordo com o clima da região.

\section{REFERÊNCIAS BIBLIOGRÁFICAS}

BRIX, H. Functions of macrophytes in constructed wetlands. Water Science and Technology, v. 29, n. 4, p. 71-78, 1994.

COOPER, P. F.; FINDLATER, B. Constructed Wetlands in Water Pollution Control: Proceedings of the International Conference on the Use of Constructed Wetlands in Water Pollution Control, Held in Cambridge, UK, 24-28 September 1990. Elsevier, 2013. ISBN 1483149986.

DE SOUSA, J. T. et al. Pós-tratamento de efluente de reator UASB utilizando sistemas "wetlands" construídos. Revista Brasileira de Engenharia Agrícola e Ambiental, v. 4, n. 1, p. 87-91, 2000.

KADLEC, R. H. et al. Constructed wetlands for pollution control. IWA, London, 2000.

MEYER, D. et al. Modelling constructed wetlands: scopes and aims-a comparative review. Ecological Engineering, v. 80, p. 205-213, 2015.

SALATI, E.; SALATI, E. Wetland projects developed in Brazil. Water science and technology, v. 40, n. 3, p. 19-25, 1999.

SEZERINO, P. et al. Nutrient removal from piggery effluent using vertical flow constructed wetlands in southern Brazil. Water science and technology, v. 48, n. 2, p. 129-135, 2003.

SIRACUSA, G.; LA ROSA, A. Design of a constructed wetland for wastewater treatment in a Sicilian town and environmental evaluation using the emergy analysis. Ecological Modelling, $v$. 197, n. 3, p. 490-497, 2006. 